PERSPECTIVA TEOLÓGICA ADERE A UMA LICENÇA CREATIVE COMMONS ATRIBUIÇÃO 4.0 INTERNACIONAL - (CC BY 4.0)

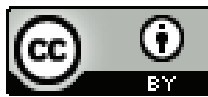

DOI: $10.20911 / 21768757 v 53 n 2 p 463 / 2021$

\title{
"FAREMOS NELE MORADA": A INTIMIDADE ENTRE JESUS E SEUS SEGUIDORES E A UNIDADE DO EVANGELHO DE JOÃO
}

"We will Make our Home with Him": the Intimacy Between Jesus and his Followers and the Unity of the Gospel of John

Vanderlei Dorneles *

RESUMO: O debate acadêmico acerca da unidade literária do quarto evangelho se desdobra em inúmeros desafios narrativos, textuais e exegéticos. Aparentes rupturas no fluxo da narrativa, dados de geografia e topografia e informações desencontradas levaram alguns estudiosos a propor esquemas de reorganização do texto de João. No entanto, estudos literários mais recentes indicam estruturas de organização interna e sistemas temáticos unificadores ao longo desse evangelho. Este artigo apresenta uma breve revisão da questão para em seguida tratar do tema unificador da relação íntima e de pertença entre Jesus e seus seguidores, possibilitada pela descida do Espírito. Essa relação se aprofunda nos discursos de despedida em João 13-17, mas que também se enraíza por todo o livro. O tema da relação de proximidade evidencia uma sólida unidade entre o prólogo do evangelho e suas duas seções maiores: Jesus e o mundo (1-12) e Jesus e seus discípulos (13-17).

PALAVRAS-CHAVE: Evangelho de João. Estudos críticos. Unidade literária. Narrativa. Teologia.

ABSTRACT: The academic debate about the literary unity of the fourth gospel unfolds in innumerable narrative, textual, and exegetical challenges. Apparent disruptions in the flow of the narrative, geographic and topographic data, and mismatched information have led some researchers to propose reorganizing schemes to the text of John. However, more recent literary studies have indicated

* Centro Universitário Adventista de São Paulo, Engenheiro Coelho, São Paulo, Brasil. 
internal organizing structures and unifying thematic systems throughout the fourth gospel. This article presents a brief review of the issue, in order to address the unifying theme of the intimate relationship and belonging between Jesus and his followers, allowed by the descending of the Holy Spirit. This relationship deepens in the farewell speeches in John 13-17, but also takes root throughout the entire book. The theme of the relationship of closeness shows a solid unity between the prologue of the gospel and its two major sections: Jesus and the world (chaps. 1-12), and Jesus and his disciples (13-17).

KEYWORDS: Gospel of John. Critical Studies. Literary Unity. Narrative. Theology.

\section{Introdução}

$\mathrm{O}$

evangelho de João apresenta à primeira vista uma unidade teológica bem arranjada, cujo núcleo narrativo é a pessoa de Cristo. O tema principal e o objetivo do livro são retomados em João 20:31, como sendo uma exposição da identidade messiânica de Jesus a partir dos "sinais" que ele manifestou, a fim de que as pessoas cressem nele como "o Cristo, o Filho de Deus" e, crendo, tenham "vida em seu nome". O texto apresenta uma estrutura com sete sinais principais (Jo 2:1-11; 4:46-54; 5:1-18; 6:1-15; 6:16-21; 9:1-12; 11:1-46), seguidos de diversos discursos sobre a origem e missão de Cristo como o messias em atuação no mundo.

Estudos histórico-críticos, porém, levantam diversos problemas à unidade literária do quarto evangelho em vista de interrupções e inconsistências da sequência narrativa, repetições e/ou passagens fora de contexto e por diferenças de vocabulário e de estilo na língua grega (cf. BROWN, 1966; TEEPLE, 1974). Entretanto, estudos mais recentes em crítica literária têm reafirmado a unidade temática do quarto evangelho (cf. MLAKUZHYIL, 2011). De acordo com estes estudos, as aparentes e mesmo evidentes rupturas textuais podem ser amenizadas quando se considera a unidade temática de toda a narrativa.

Este artigo explora a relação íntima e de pertença entre Jesus e seus seguidores como um tema unificador que projeta uma visão de conjunto no texto desse evangelho. O objetivo desta análise é indicar que, se não é evidente uma unidade em termos de narrativa, cronologia e geografia, do ponto de vista temático e literário o texto evidencia uma clara organização interna.

\section{Rupturas textuais em João}

Os estudos histórico-críticos modernos despertaram a percepção de diversos desafios e problemas textuais e históricos nos evangelhos, como em todo o texto bíblico. Barton (2010, p. 37) afirma que, na tarefa de "preservar, 
transmitir e interpretar as tradições sobre Jesus", o Novo Testamento integra elementos históricos e textuais da Bíblia Hebraica e sua versão grega (Septuaginta), além de tradições e visão de mundo da antiguidade greco-romana em geral, o que torna a interpretação do diversificado material bíblico um grande desafio. Além disso, Ehrman (2010, p. 127) acrescenta que antes de explorar o que um texto bíblico significa, o intérprete precisa saber o que esse texto é e que palavras originalmente lhe pertencem e aquelas que lhe foram acrescidas em seu processo de transmissão. $\mathrm{O}$ caso do quarto evangelho é exemplar nesse sentido, havendo grande número de trechos e termos aparentemente incorporados ao longo de sua editoração e transmissão.

A partir de sua perspectiva histórico-crítica, Brown (1966, pp. xxiv-xxvii) aponta vários problemas no fluxo narrativo e nas informações geográficas no evangelho de João. Segundo ele, também "há diferenças de estilo no grego do evangelho". Com base nisso, Brown sugere que o texto final pode ser resultado de fontes diversas em termos de estilo e informação, bem como de múltiplos processos de edição e redação. Carson (2011, p. 35) afirma que Brown foi "relutante" em aplicar o termo "crítica da fonte" a seu trabalho. No entanto, ele afirma que Brown termina por indicar "cinco camadas de tradições que refletem o desenrolar da história da comunidade joanina" (cf. CARSON, 2011, p. 37). Em reação, Barrett defende que o próprio evangelho "desafia a análise precisa de suas fontes", embora isso não signifique que fontes não foram usadas em sua construção, mas que "essas fontes (exceto Marcos) não podem ser identificadas" (BARRET, 1967, p. 18).

Além das questões de composição, Brown (1966, p. xxiv) propõe que o prólogo de João emprega "importantes termos teológicos" não encontrados no corpo do livro, por exemplo lógos (palavra, personificada), charis (graça ou amor pactuante) e plèroma (plenitude). Brown ainda atesta haver "quebras e inconsistências nas sequências", "repetições nos discursos, bem como passagens que claramente não pertencem ao contexto" (1966, p. xxv). Em vista disso, segundo ele (1966, p. xxiv), muitas tentativas têm sido feitas para resolver os "saltos" geográficos e cronológicos em João. Em relação às passagens claramente fora de sequência, acredita que uma reorganização das mesmas pelo corpo do texto resolveria alguns sérios problemas do evangelho (BROWN, 1966, p. xxvi).

Nessa perspectiva crítica, o evangelho parece um amontoado de narrativas de fontes prévias diversas, e mesmo um processo editorial posterior não teria sido suficiente para ajustar os fragmentos de forma a apresentar uma sequência lógica e coerente. Em vez disso, os fragmentos parecem mal-arranjados, evidenciando rupturas narrativas.

Admitindo essas rupturas, Barrett $(1967$, p. 18) afirma que a narrativa de João não flui de forma direta e que algumas das conexões são ruins, e parece "às vezes não haver conexões de forma nenhuma". Nesses casos, 
um processo editorial mecânico de deslocamento de alguns trechos tornaria a leitura mais fluente. Barrett $(1967$, p. 19) destaca que os esquemas de "deslocamentos" e rearranjos que, em geral, têm consenso são os seguintes: (1) João 3:22-30 parece interromper o discurso com Nicodemos (3:31 segue 3:21) e poderia ser removido para estar entre 2:12 e 2:13. Essa mudança esclareceria o itinerário, uma vez que Jesus, da Galileia em 2:1-12, foi em seguida para a Judeia em 3:22, antes de ir para Jerusalém em 2:13. (2) O cap. 6 poderia estar entre o 4 e o 5, porque, conforme o evangelho está, Jesus vai para a Galileia em 4:54, se dirige a Jerusalém em 5:1, atravessa o mar da Galileia em 6:1; mas sem indicação de que ele deixou Jerusalém, caminha na Galileia, não podendo caminhar na Judeia em 7:1, porque os judeus queriam matá-lo, embora ele não tivesse estado em Jerusalém desde 5:47. Se essa mudança é feita, o curso dos eventos melhora: Jesus estaria na Galileia em 4:54; atravessaria o mar em 6:1; e iria a Jerusalém em 5:1; e retornaria, por questão de segurança, para a Galileia em 7:1. (3) João 7:15-24 poderia ser lido após 5:47, pois continua o argumento do cap. 5 e interrompe a conexão entre 7:14 e 7:25. (4) João 10:19-29 deveria ser lido após 9:41, pois a "divisão" de 10:19 segue naturalmente o sinal do cap. 9 e assim faz a remarca de 10:21. Em seguida, de forma surpreendente, João 10:18 é retomado em 10:30. (5) Os caps. 15 e 16 poderiam ser colocados em algum ponto antes de 14:31, como fechamento dos discursos do cenáculo. Por fim, (6) João 18:13-24 está fora de ordem, pois é difícil de entender o movimento de Jesus diante de Anás e Caifás.

Nesta mesma perspectiva, Metzger (1994, p. 219-222) acrescenta que o relato acerca de João Batista em João 1:6-8 interrompe o fluxo do prólogo de 1:1-18, sendo que o v. 9 parece continuá-lo. Depois, o diálogo de João Batista com os discípulos em 3:22-30 interrompe o discurso maior cujo orador é Jesus. Nesse caso, João 3:31-36 parece continuar o discurso de 3:1-21, com elementos comuns nos dois relatos. Na sequência, o discurso sobre o "pão da vida" em João 6:35-40 parece duplicado no da eucaristia em 6:51-58. A perícope de João 7:53-8:11 parece inserir um relato mais tardio e de estilo diverso, visto por muitos como um texto de fonte não joanina. Alguns entendem que João 20:30-31 faz uma clara conclusão do evangelho, mas então segue o capítulo 21. Por fim, parece haver dois discursos de despedida (Jo 13:31-14:31; 15:1-16:33), sendo que o segundo repete muitos temas do primeiro (cf. 13:33 e 16:16-17; 13:34 e 15:12; 14:1314 e $16: 23-24 ; 14: 15$ e $15: 10 ; 14: 16$ e $15: 26 ; 16: 13-15)$.

Apesar dessas dificuldades para se ajustar a ordem das narrativas joaninas, o intérprete de João precisa considerar a questão crucial acerca de qual seria o elemento organizador das narrativas desse evangelho, se a cronologia e a geografia, ou a teologia. Diante disso, Barrett (1967, p. 20) defende que, ao propor o deslocamento de certos trechos em João, o pesquisador deve considerar que (1) não há evidências textuais que apoiem algum tipo de deslocamento; (2) João não se interessa por itinerários, e "o movimento 
do evangelho é ditado por considerações teológicas em vez de aspectos topográficos e geográficos"; e (3) embora as alterações propostas em geral melhorem as conexões, elas "criam outros problemas piores".

George Mlakuzhyil também concorda com os principais problemas narrativos levantados pelos estudos críticos do quarto evangelho. Ele faz um resumo das "aporias" que desde o século XIX são apontadas pelos comentaristas (MLAKUZHYIL, 2011, p. 35-39). Para ele, esses problemas podem ser agrupados em três principais: (1) emprego de termos atípicos, (2) interrupções no fluxo da narrativa, e (3) inserções e mudanças temáticas ou geográficas abruptas ou inconsistentes. Entre os termos atípicos, Jesus é chamado de lógos em João 1:1 e 14, não sendo essa designação retomada no restante do evangelho (cf. Ap 19:13). O verbo skēnoō ("tabernaculizar") é usado somente em João 1:14 (cf. Ap 7:15; 12:12; 13:6; 21:3). Por fim, em João 12:47 usa-se o verbo phylassō em vez do usual tereō, empregado 11 vezes para "guardar os mandamentos" ou "guardar as palavras" (cf. Jo $14: 15 ; 15: 10)$.

Entre as informações inconsistentes, em João 2:11 consta que a transformação da água em vinho, em Caná, é o "princípio" dos sinais, mas 2:23 afirma que Jesus fez outros sinais em Jerusalém; mesmo assim, a cura do filho do oficial em 4:54 é relatada como o "segundo sinal". Além disso, em João 3:22 e 4:1 consta que Jesus batizava, mas em 4:2 é dito que "Jesus mesmo não batizava, e, sim, os seus discípulos". Também João 13:36 relata que Pedro pergunta a Cristo: "Senhor, para onde vais?", mas em 16:5 Jesus afirma: "nenhum de vós me pergunta: para onde vais?" Por fim, em João 14:31, Jesus chama os discípulos: "Levantai-vos, vamos daqui", mas a verdadeira partida do Cenáculo só é reportada em 18:1, após o longo discurso de João 15-16 e a oração de João 17.

Diante das soluções propostas, no entanto, Mlakuzhyil (2011, p. 39) argumenta que os deslocamentos criam grandes problemas. Por exemplo, se a ordem dos cap. 5 e 6 é invertida, a evidente inconsistência geográfica de 6:1 e 7:1 desaparece, mas isso destrói a sucessão do simbolismo teológico do pão e da água nos caps. 6 e 7. Esta sucessão "ecoa a estória do êxodo em que Deus proveu a Israel pão do céu e água da rocha" (MLAKUZHYIL, 2011, p. 40). Além disso, reorganizar literariamente o texto implica sempre o perigo de impor a ele a própria visão do intérprete, em detrimento da lógica narrativa e teológica originalmente pretendida para o evangelho.

Além disso, Mlakuzhyil (2011, p. 43) considera que algumas inconsistências são criadas pelos próprios intérpretes. Por exemplo, ele argumenta que o texto não reza que o sinal da água transformada em vinho é o "primeiro sinal" (prōton sèmeiōn), mas que é o "princípio dos sinais" (arkēn tōn sēmeiōn, 2:11). Os capítulos 2-4 não descrevem, mas somente mencionam de passagem "os sinais" que Jesus fez em Jerusalém (2:23; 4:45; cf. 3:2). Além disso, a cura do filho do oficial não é simplesmente chamada de "segundo sinal"; 
o texto declara que "foi este o segundo sinal que fez Jesus, depois de vir da Judeia para a Galileia" (Jo 4:54). Por desdobramento, cada lacuna ou fragilidade literária no texto pode ser objeto de estudo para se definir por que o texto tem essa característica e não outra.

A despeito dessas questões, Mlakuzhyil (2011, p. 35) propõe que uma estrutura literária é perceptível no quarto evangelho, o que pressupõe uma "unidade literária" original. Barrett defende também que o evangelho evidencia "uma unidade genuína de linguagem e estilo" (1967, p. 20). Por sua vez, Kostenberger (2009, p. 167) acrescenta que uma ordem narrativa é claramente percebida, sendo "um grande consenso entre os eruditos" que o quarto evangelho tem uma "introdução" (Jo 1:1-18), seguida da primeira unidade temática chamada de "O livro dos sinais" (1:19-12:50) e uma segunda unidade chamada de "O livro da glória" (13:1-20:31), além do epílogo intencional (21:1-25).

Assumindo-se que o livro tenha uma estrutura intencional, a unidade literária do mesmo pode ser defendida a partir de uma visão de conjunto baseada em sua unidade temática e teológica. Tal unidade pode ser destacada a partir do tema da proximidade íntima entre Jesus e seus discípulos, enfatizada no discurso de despedida (Jo 13-17), como resultado da crença nele como messias e que resulta na admissão como "filhos de Deus" (Jo 1:12).

\section{A organização da narrativa joanina}

Nessa perspectiva, o evangelho pode ser lido tendo em mente uma ordem narrativa controlada não necessariamente pelos dados cronológicos e geográficos, mas por interesses temáticos e teológicos. Esses critérios são pertinentes quando se considera que o quarto evangelho foi o último dos quatro a ser escrito, o que atribui ao texto um valor teológico e conceitual muito mais amplo do que o cronológico-narrativo.

Os eruditos concordam que o prólogo do evangelho de João introduz os grandes temas e as próprias divisões da narrativa, projetando uma estrutura literária para o conjunto do texto. Lenski (1961, p. 25) defende que "o prólogo resume todo o conteúdo do evangelho". Barrett (1967, p. 126) argumenta que "muitas ideias centrais no prólogo são igualmente centrais no corpo do evangelho". Como parte do prólogo, João 1:11-12 parece resumir todo o conjunto do livro, ao afirmar que Jesus veio para os seus, e estes "não o receberam"; mas a todos que o receberam deu-lhes a condição e o status de serem chamados "filhos de Deus", a saber os que "creem" no seu nome. Esses dois grandes temas são desdobrados nas seções de João 2-12, e 13-17, respectivamente. Desta forma, o prólogo, 
mais especificamente João 1:11-12, faz uma projeção da temática central a ser explorada na sequência do livro.

Sobre os termos-chave, ao contrário do que pontua Brown (1966, p. xxiv-xxv), há diversos termos e conceitos introduzidos brevemente no prólogo e que são desdobrados ao longo do livro. Entre esses, podem se destacar, por exemplo, zōe ("vida", Jo 1:4; empregado outras 35 vezes no livro, cf. 3:15; 4:36; 6:40; 10:10; 20:31), martyría ("testemunho", v. 7; outras 13 vezes, cf. $3: 11 ; 5: 32 ; 8: 13 ; 19: 35)$, alēthinós ("verdadeiro", v. 9; outras 8 vezes, cf. 4:37; 8:16; 17:3; 19:35), kósmos ("mundo", v. 10; outras 78 vezes, cf. 3:19; 7:4; 12:19; 14:27; 18:37), dócsa ("glória", v. 14; outras 18 vezes, cf. 5:41; $8: 54 ; 11: 40 ; 17: 22$ ) e alētheia ("verdade", v. 14, outras 24 vezes, cf. 3:21; 8:32; 14:17; 17:19). Do ponto de vista terminológico, portanto, o prólogo antecipa os grandes temas do livro como um todo, embora termos como lógos e skēnoō pareçam ser esquecidos depois.

Na sequência do prólogo, as seções de 1:15-12:50 tratam da rejeição a Jesus e detalham a afirmação de João 1:11: “Veio para o que era seu, e os seus não o receberam". Incredulidade e confronto entre Jesus e os líderes judeus são narrados sucessivamente, mesmo em vista dos sinais ou por causa deles (Jo 2:18-22; 5:18, 38-47; 6:30, 41-42, 66-71; 7:14-24; 8:33, 44, 48-53; 9:13-34). Com base nas alegações dos judeus em João 9:24-34, Hendriksen (2007, p. 87) afirma que, nesta primeira seção, os judeus tentam provar de todas as maneiras possíveis que Jesus não é o "enviado de Deus", apesar do sinal da cura do cego que eles não conseguiam esconder. Em João 10, a rejeição a Jesus continua. Em 10:20, os judeus entram em dissensão, e uns dizem: "Ele tem demônio e enlouqueceu". Em 10:39, o texto reza: "Nesse ponto, procuravam, outra vez, prendê-lo; mas ele se livrou das suas mãos". No capítulo 11, após a ressurreição de Lázaro, os judeus planejam tirar a vida de Jesus (v. 47-57). E ainda no capítulo 12, os judeus permanecem incrédulos: "Embora tivesse feito tantos sinais na sua presença, não creram nele" (12:37). Alguns dentre as "próprias autoridades creram", mas "amaram mais a glória dos homens do que a glória de Deus" (12:42-43). Tenney (1981, p. 133) considera que a referência ao "servo sofredor" de Isaías 53, em João 12:37-38, indica que "a incredulidade estava rapidamente se aproximando de seu clímax com a rejeição e crucificação de Jesus", o que evidencia a rejeição por parte daquela geração dos líderes judeus à "revelação" divina por meio do messias. Desta forma, os capítulos 11 e 12 , com a decisão da parte dos judeus de tirar a vida de Jesus, mostram o clímax da rejeição anunciada resumidamente em João 1:11. Carson (2011, p. 447) afirma que João sumariza nesta seção a "verdade apresentada em todo o quarto evangelho", que de forma consciente "a nação de Israel, de modo geral, recusou a regeneração por intermédio do Espírito que está no núcleo da prometida nova aliança", o que segundo ele já estava estabelecido no prólogo de João 1:10, 11. 
Na sequência, os eventos narrados nos capítulos 12 e 13 sugerem uma transição entre as duas grandes seções narrativas do evangelho. Para alguns, há uma clara divisão no fechamento do capítulo 12: "Cristo deixa as multidões e se volta para o círculo mais íntimo dos discípulos" (HENDRIKSEN, 2007, p. 64). Em João 12:37-50, “o ministério público de Jesus se encerra; ele retorna para a obscuridade de onde emergiu (11:54; 12:1) para fazer seus últimos discursos" (BARRETT, 1967, p. 358). A partir de então, ele mantém somente conversas privadas com os discípulos. A fala dos v. 12:44-50 é "um epílogo em vez de um discurso dentro da estrutura principal da narrativa" (BARRETT, 1967, p. 358). O capítulo 13 é narrativo, enquanto os capítulos 14-17 registram discursos de Jesus aos discípulos, ou àqueles que o aceitaram. Portanto, João 13 pode ser visto como uma introdução natural, que descreve o ambiente e a circunstância dos discursos do Cenáculo (cap. 13-17).

Nessa perspectiva, o discurso de João 12:44-50 pode ser visto como um resumo dos fatos narrados até então e uma avaliação à luz do programa do evangelho estabelecido em João 1:11-12. Jesus divide a audiência em dois grupos: "Quem crê em mim, crê não em mim, mas naquele que me enviou" (12:44) e "Quem me rejeita e não recebe as minhas palavras tem quem o julgue" (12:50). O duplo propósito do evangelho fica evidente: ao mesmo tempo que traz salvação aos que creem, ele também implica juízo e condenação aos descrentes (CARSON, 2011, p. 452). Os discursos que seguem (cap. 13-17) tratam da atenção especial de Jesus aos que o receberam, detalhando a afirmação de João 1:12: "Mas, a todos os que o receberam, deu-lhes o poder de serem feitos filhos de Deus". Desta forma, essa dupla divisão do texto de João segue a agenda narrativa estabelecida no prólogo em 1:11 e 12.

Portanto, a divisão narrativa em dois blocos, servindo os capítulos 12-13 como o fechamento e a transição para o segundo bloco, parece intencional e evidencia a estrutura deliberada do quarto evangelho. Essa divisão também prepara o leitor para os discursos de despedida, nos quais Jesus dedica especial atenção aos que o receberam. Nestes capítulos, ele aprofunda a exposição da relação íntima possibilitada entre ele e esses seguidores por causa da fé despertada em sua pessoa.

\section{Despedida, separação e retorno}

Uma vez que os discursos de João 12:44-50 constituem uma transição para a segunda grande unidade narrativa do evangelho, os capítulos seguintes desdobram a previsão de João 1:12. Jesus proporciona aos que creem o privilégio da paternidade divina na família celestial. Os discursos dessa seção são exclusivamente dirigidos ao círculo íntimo dos que creram em Jesus como o messias. 
João 13 narra o rito de humildade (13:5) e o partir do pão $(13: 18,26)$, os quais sinalizam a reunião íntima de Jesus com os discípulos e dão a circunstância dos discursos que seguem. Em João 14, sentindo chegar a "hora" de sua partida (2:4; 7:30; 8:20; 12:23; 13:1; 17:1), Jesus procura confortar os discípulos que temiam a separação iminente do mestre. Neste contexto, "o Senhor lhes assegura que sua partida para a casa do Pai tinha o propósito de uma reunião, e que não seria uma separação permanente" (HENDRIKSEN, 2007, p. 265). A partida anunciada por Jesus parece ser, portanto, um conjunto de eventos incluindo sua morte, ressurreição e ascensão ao Pai para a decorrente mediação. Carson (2011, p. 455) pontua que o propósito dessa unidade temática (Jo 13-17) é "revelar", antes do evento, o significado e resultado da partida (morte, sepultamento, ressurreição e exaltação) de Jesus, a saber, a construção dos laços de intimidade e pertencimento entre Jesus e os que creem.

Neste contexto, Jesus está diante de sua partida, o retorno para a companhia do Pai, após a encarnação e o ministério terrestre. O propósito final dessa partida, no entanto, é uma aproximação ainda mais íntima com a humanidade. Paradoxalmente, essa partida o conduzirá para mais próximo de seus seguidores do que sua própria encarnação.

Nesta linha de pensamento, a afirmação de Jesus em João 14:3, de que voltaria "outra vez" assume uma importância central. Ao mesmo tempo que afirma estar de partida, ele fala de seu retorno. O texto é entendido tradicionalmente como uma referência à escatológica segunda vinda, o que se reflete em algumas traduções bíblicas (cf. Jo 14:1-3, "voltarei e os levarei", NVI, cf. NTLH). O próprio Carson (2011, p. 489) defende que "os detalhes do texto [14:1-3] demonstram que estes dois versículos se referem ao segundo advento de Jesus, quando ele vem para levar seus seguidores para estarem com ele para sempre". Para ele, a expressão de 14:2, "na casa de meu Pai" se refere ao Céu, onde "há muitos aposentos" e para onde os discípulos finalmente irão com Jesus após sua segunda vinda (CARSON, 2011, p. 489).

A proximidade e o tom íntimo de Jesus nesta seção (13-17) não parecem se ajustar a tal promessa voltada para um evento escatológico muito distante no tempo. Visto por outra perspectiva, o discurso de João 14:1-3 pode ser uma referência ao aprofundamento da relação de pertença e proximidade entre Jesus e os discípulos, algo que está para ocorrer em resultado de sua "partida". Como veremos, essa interpretação, em grande medida, depende do sentido atribuído às palavras "casa" e "moradas", em João 14:2.

Observando-se o contexto e os tempos verbais, de fato, a afirmação de Cristo parece indicar outro tipo de "retorno". O verbo paralambánō (14:3) está no indicativo futuro ("receberei"), mas erkomai está no indicativo presente ("volto"), embora seja muitas vezes traduzido como futuro ("voltarei", ARC). O verbo eimí também está no indicativo presente ("estou"), 
embora às vezes seja traduzido como subjuntivo futuro ("estiver"). $\mathrm{O}$ verbo paralambánō pode significar "levar" ou "tomar" (para si ou consigo), ou "aceitar" e "receber", denotando entrada em companheirismo. Assim, a ARA traduz como "vos receberei", em vez de "vos levarei" (NVI). Em João 14:18, Jesus declara: "Não vos deixarei [aphiémi, indicativo futuro] órfãos; voltarei [erkomai, novamente no indicativo presente; 'volto'] para vós outros." Desta forma, considerando a afirmação de João 14:16 de que Jesus rogará ao Pai, a fim de que envie "outro Consolador", o texto de João 14:18 parece indicar que, por meio do Espírito, Jesus "voltaria" para estar mais próximo ainda dos discípulos. Nesse caso, a promessa de Jesus no discurso de despedida não parece tratar sobre a vinda escatológica distante, mas sobre sua presença íntima com os discípulos mediante o Espírito consolador. Logo, a frase "a fim de que esteja para sempre convosco" (Jo 14:16) pode ser entendida como "para estar no meio de vocês", indicando associação íntima. A preposição metá ("com") tem o sentido básico de estar "no meio de" ou "em união com" (ARNDT; GINGRICH, 1960, p. 509-511; RUSCONI, 2011, p. 303-304 ).

O "retorno" de Jesus, portanto, prometido em João 14:1-3 deve ser entendido em termos da descida do Espírito. Neste contexto, Bruce (1981, p. 255) afirma que "João não aborda a dimensão cósmica da volta do Senhor", a tomar lugar por ocasião da parousía. Em vez disso, a sua "vinda" é apresentada aqui como a "consumação da comunhão entre ele e seus discípulos". Neste caso, o Espírito viria para habitar com os discípulos, a fim de estreitar a relação entre estes e o Messias. Eles passariam, assim, a ser "morada" pessoal e permanente do Espírito (cf. Jo 7:39; 14:23; 1Cor 3:16; 2Cor 6:16; Ef 2:21). À luz de João 14, pode-se dizer que "na nova dispensação, começando com o derramamento do Espírito, os discípulos e aqueles que depois deles abraçassem a Cristo por meio da fé entrariam em relacionamento íntimo com o Pai e o Filho" (HENDRIKSEN, 2007, p. 280).

No contexto do quarto evangelho, Jesus afirma dois diferentes tipos de relação com o Pai: ele "está no Pai, e o Pai em mim" (Jo 14:11), referindo-se a sua condição de unidade espiritual com o Pai. No entanto, também declara: "eu vou para junto do Pai" (Jo 14:12), em referência à sua ascensão após a ressurreição, quando passaria a "rogar ao Pai" para que enviasse o Consolador (14:16). Desta forma, a expressão "naquele dia" (Jo 14:20) se refere ao dia em que Jesus terá retornado ao Pai e enviado o Espírito para estar com seus discípulos. “Então eles aprenderão de maneira nova a verdade desta unidade mútua com o Pai sobre a qual eles tantas vezes o tinham ouvido falar" (BRUCE, 1981, p. 261).

O discurso de despedida, portanto, começa com uma afirmação de Jesus de que a separação entre ele e os que creram não seria definitiva nem prolongada. Por meio do Espírito, ele retornaria para estar ainda mais próximo deles. 


\section{Moradas preparadas}

Curiosamente, ao mesmo tempo que afirma que "voltaria" para seus discípulos, Jesus também afirma que prepararia "moradas" para eles na "casa" do Pai (Jo 14:2). O sentido da palavra "morada" (monē) neste texto parece crucial no entendimento de toda unidade temática de João 13-17. A "morada" que Jesus afirma preparar para os que nele creram pode ser um novo status ou espaço como filhos e membros da família de Deus, o que daria sentido à expressão "não vos deixarei órfãos" (Jo 14:18) e desdobraria naturalmente a segunda parte do programa narrativo estabelecido em João 1:11-12: "mas, a todos quantos o receberam, deu-lhes o poder de serem feitos filhos de Deus".

A tradução "na casa de meu Pai há muitas moradas" (ARA) reflete a compreensão tradicional da passagem em que a expressão "casa de meu Pai" é tomada como referência ao Céu para onde Jesus iria e de onde voltaria outra vez (ver CARSON, 2011, p. 489; MORRIS, 1995, p. 567). Nessa mesma linha, Brown (1966, p. 625) afirma que provavelmente "casa de meu Pai" deva ser entendida como o "Céu". De fato, a palavra "morada" (do verbo latim moráre, "demorar-se", "ficar") indica os compartimentos de palácios ou castelos, lugares onde se vive ou se hospeda. Mas uma "casa" tem "quartos", não exatamente "moradas". Bruce (1981, p. 255) destaca que o substantivo monē, ligado ao verbo ménō ("ficar"), ocorre só duas vezes no Novo Testamento (Jo 14:2, 23), e tem o sentido de "um lugar para ficar"; havendo diversos lugares assim numa casa, "quartos" seria a tradução mais natural. No entanto, uma vez que neste contexto do quarto evangelho monē está ligado a oikía ("casa"), o sentido aqui poderia ser de "espaço" ou condição de convivência, pois oikía também se refere a uma "família", como em João 4:53, quando se diz que toda a "casa" do centurião "creu" em Jesus (cf. Lc 18:29). Desta forma, a fala de Jesus pode ser interpretada como: "na família de meu Pai há muitos lugares". E ele vai tomar providências para receber os discípulos nessa família. Nota-se que a presença contínua de Jesus com seus discípulos está "no coração do discurso de despedida de Jesus nos capítulos 14 e 15" (BALZER, 2008, p. 115).

Nesta perspectiva, a expressão "casa de meu Pai" em 14:2 deve ser entendida em comparação com "casa de meu Pai" em 2:16, onde a referência é ao templo de Jerusalém, com o emprego da palavra oikos, em vez de oikía. Apesar de João empregar tanto oikía quanto oikos em referência ao "prédio" onde vive uma família (ver Jo 7:53; 11:20; 11:31; 12:3), o contexto pode indicar certa distinção entre os termos. Em João 8:35, ao afirmar que o "escravo não fica para sempre na casa (oikía), mas o filho sim", Jesus indica que a permanência na família de Deus depende da fé nele (cf. 1:12-13). Diante disso, é possível que João 14:2 retome oikía com o sentido de "família" e monē como "permissão/condição de permanência". Brown (1966, p. 627) concorda haver precedente para se entender a expressão "na casa de meu Pai há muitas moradas" como uma parábola para a "permanente união 
(monē/ménō) com o Pai por meio de Jesus". Neyrey (2002, p. 70) também entende que "casa de meu Pai" não deve ser entendida como o Céu, mas "como a família de Deus aqui na terra", o que para ele é uma metáfora "social, não espacial". Para Aune (1972, p. 130), a imagem da "família" de Deus em 14:2 e 8:35 "reflete a autodesignação da comunidade joanina" (ver também 1Pe 2:5; 4:17; 1Tm 3:15; Hb 3:2-6). Por isso, parece convincente pensar que, em vista das "muitas referências a ménō nos capítulos 14-17, todas com foco em uma habitação pessoal em um futuro imediato, em vez de um futuro escatológico, seja preferível ver monai pollai ['muitas moradas'] como se referindo às muitas habitações pessoais dentro da nova família do Pai por parte de filhos e filhas espirituais" (BALZER, 2008, p. 118).

Isso fica ainda mais claro quando se considera que a mesma "morada" (monē) que Jesus declara haver na "casa" do Pai, nas quais ele vai preparar "lugar" (14:2), os discípulos devem prover para ele e o Pai, neles mesmos: "Se alguém me ama, guardará a minha palavra; e meu Pai o amará, e viremos e faremos nele morada [monē]" (Jo 14:23). Nesse caso, mone ("morada") aqui tem mais o sentido de "lugar" do que de "quartos". Jesus vai preparar "lugar" no sentido de que sua intercessão criará as condições de pertença e inclusão permanentes para seus discípulos como filhos na família do Pai.

Portanto, o objetivo da ida de Jesus para o Pai, mediante a morte, ressurreição, ascensão e glorificação, é conquistar "espaço" para os discípulos na "família" do Pai. Isso se ajusta ao programa do evangelho estabelecido em João 1:12: "Mas, a todos quantos o receberam, deu-lhes o poder [exousía, 'autoridade', 'poder', 'direito'] de serem feitos filhos de Deus". Sendo filhos por meio da fé em Cristo, têm "espaço" na família do Pai. Hendriksen (2007, p. 284) propõe que, neste caso, a frase "e nele faremos morada" indica um relacionamento "íntimo e profundo" entre Jesus, o Pai e os discípulos. Trata-se de uma relação de intimidade e pertença que está sendo construída mediante a morte, ressurreição e ascensão de Jesus.

A habitação, ou morada, de Jesus nos discípulos tem eco na mensagem de Cristo a Laodiceia: "Eis que estou à porta e bato; se alguém ouvir a minha voz e abrir a porta, entrarei em sua casa e cearei com ele, e ele, comigo" (Ap 3:20). A mesma relação íntima ou de pertença é assegurada aos que abrem a porta ou aceitam o Cristo exaltado.

Bruce (1981, p. 262) destaca que a presença de Deus e de Cristo se concretiza onde "amor e obediência são mostrados". Assim, Pai e Filho, juntos, vêm habitar em cada discípulo tornado filho. Em Sobre a Trindade, 15.27, Agostinho levou este pensamento um pouco mais longe, ligando o ensino das passagens sobre o Consolador com o de seu contexto. De acordo com ele, "o Espírito é o vínculo do amor (vinculum caritatis) que une Pai e Filho, e é a expressão plena do amor que flui entre o que ama e o Amado" (apud BRUCE, 1981, p. 261). Beasley-Murray (1987, p. 249) 
destaca que, desta forma, a promessa feita em João 14:1-3 se relaciona com a comunhão que será possibilitada por meio da ascensão de Cristo e de seu retorno por meio do Espírito. Segundo ele, o retorno de Jesus para seus discípulos tem a finalidade de "um mútuo relacionamento dentro da 'casa' no presente" (BEASLEY-MURRAY, 1987, p. 249).

Nessa linha de pensamento, a "volta" de Jesus anunciada no discurso de despedida, no contexto de João 14-17, ocorre por meio do Espírito e tem a finalidade de consumar a relação íntima e de pertencimento entre ele e seus discípulos (cf. BEUTLER, 2016, p. 342-ss). Hendriksen (2007, p. 265) propõe que "independentemente da morte de Cristo e do trabalho do Espírito Santo não haveria lugar no Céu [ou na família de Deus] para os discípulos".

O preparo de "lugar" ou "espaço" na família do Pai para os que creem em Jesus indica a relação de pertencimento e familiaridade em que os discípulos entram a partir da ligação pessoal deles com Cristo. Esta perspectiva de proximidade e pertencimento em João 14, como o centro da unidade narrativa de João 13-17, encarece a estrutura narrativa do quarto evangelho. Sob este ponto de vista, o programa estabelecido no prólogo do evangelho encontra seu ápice no centro do livro, além de permear todo o conjunto narrativo.

\section{A proximidade 'face a face'}

O ponto central do discurso de despedida parece ser a possibilidade que desponta de uma nova relação de pertença entre Jesus e seus seguidores, uma relação marcada por unidade ou proximidade superior àquela experimentada até então. Por meio do Espírito ou Consolador, tanto o Pai quanto o Filho viriam "para" (gr. prós, "face a face com") aquele que ama e guarda a palavra de Jesus (Jo 14:23). A preposição grega prós tem também o sentido de: "perto", "diante de", "na presença de", "para", "em", "junto", "perto de" e "diante de", além de "para". Usada de modo figurativo, ela evidencia um relacionamento "íntimo" ou "próximo a alguém" (cf. RUSCONI, 2011, pp. 391-392; ARNDT; GINGRICH, 1960, p. 716-717; ver também LOUW; NILDA, 2013, p. 637, 638-9, 704, 711).

O emprego da preposição grega prós em João 14:23 se torna significativo ao se considerar a afirmação do prólogo, em João 1:1: “E o Verbo estava com [prós, 'face a face', 'próximo'] com Deus". O significado desta construção é que "o Verbo existia no relacionamento mais íntimo possível com o Pai, e que ele tinha supremo deleite nessa comunhão" (HENDRIKSEN, 2007, p. 70). Tenney (1981, p. 28-29) acrescenta que a afirmação de que o Logos estava "no princípio com [prós] Deus" (Jo 1:1) pode ser traduzida como "o Logos estava face a face com Deus", indicando o "companheirismo entre o Logos e Deus", companheirismo este agora estendido aos discípulos. 
Neste contexto, Lenski (1961, p. 32) argumenta que a preposição prós, distinta de en, para e syn, é da maior importância, sendo a tradução "face a face com Deus" uma opção literal. Ele se refere a 625 ocorrências em que prós é usado para "relacionamento vivo, conversa íntima", o que bem descreve seu uso neste caso (Jo 14:23). "A ideia é de presença e comunhão com forte tom de reciprocidade" (LENSKI, 1961, p. 32). Para Lenski (1961, p. 32), a preposição prós indica aqui "uma comunhão inseparável com Deus, e Deus retorna de forma igual". Além disso, essa preposição em João 1:1 lança luz sobre Gênesis 1:26: "Façamos o homem a nossa imagem, conforme a nossa semelhança" (LENSKI, 1961, p. 33), no sentido de que o homem é criado para viver em relação "face a face" com a divindade. Tal relação, no entanto, foi tornada impossível por causa da condição de pecado e rebelião, mas eis que está para ser retomada pela virtude da morte e ressurreição de Jesus.

Por sua vez, Barrett (1967, p. 129) acrescenta que a partícula prós com acusativo dificilmente poderia indicar "na presença de" no grego clássico, mas este significado é "inquestionável no Novo Testamento grego" (por exemplo, em Mr 6:3). Além disso, ele ressalta que a partícula prós em João 1:1 sugere a influência da Bíblia hebraica, porque "a Sabedoria estava com [heb. etsel; gr. prós] Deus" no princípio (cf. Pr 8:30). Assim, "a Palavra não vai para estar com Deus. A Palavra [já] está com Deus no princípio" (BARRET, 1967, p. 129). Na ascensão, portanto, o Deus encarnado "retorna para a posição de glória ocupada por ele antes da criação" (BARRET, 1967, p. 130). Entretanto, quem volta é tanto o Logos que lá já estava quanto o Jesus homem ressuscitado. Tendo entrado na história, o Logos divino não se separa mais do Jesus humano. Ele volta, contudo, para a mesma posição que, como o Logos, tinha ocupado anteriormente.

Este mesmo sentido é dado pela expressão do prólogo “o Deus unigênito, que está no seio [kólpos] do Pai" (Jo 1:18). Esta mesma relação é desfrutada pelo "discípulo amado" que na ceia estava também "aconchegado [kólpos] a Jesus", ou seja, ao "peito" de Jesus (Jo 13:23). A expressão "no seio de" indica "íntima associação, pressupondo relacionamento próximo" (TENNEY, 1981, p. 34). Sobre kólpos, no contexto de João 1, Barrett afirma que o uso deste substantivo indica que "o Pai e o Filho mantêm a mais íntima comunhão" (1967, p. 141).

Portanto, quando Jesus afirma "para que, onde eu estou, estejais vós também" (Jo 14:3), ele não se refere a uma posição geográfica, mas à sua relação "face a face" com o Pai. Isso fica explicado em João 14:20: "Naquele dia, vós conhecereis que eu estou no Pai, e vós, em mim, e eu, em vós". Desta forma, a relação "face a face" que Jesus mantinha antes e ainda mantém com o Pai (Jo 1:1) será possibilitada aos discípulos pela vinda do Consolador, pois "o Espírito da verdade que o mundo não pode receber... habita convosco e estará em vós" (Jo 14:17). Além disso, a mesma relação 
"face a face" (prós) que o Verbo tem com o Pai (Jo 1:1; 14:12), terá com os discípulos, pois afirma: "vou e volto para junto [prós] de vós" (14:28).

Após a ressurreição, quando se manifestou a Maria Madalena, Jesus declarou que "ainda" não tinha subido "para (prós) o Pai", mas que faria isso em seguida: "Subo para [prós] meu Pai". Ao "cair da tarde daquele dia", quando Jesus apareceu aos discípulos, no primeiro dia de sua ressurreição, assoprou sobre eles e declarou: "recebei o Espírito Santo" (Jo 20:22), o prometido Consolador de João 14-16. Nesse momento, eles passaram então a estar também no Pai, pois Jesus tinha subido e voltado para eles por meio do Espírito. Com isso, Jesus afirma que "assim como o Pai" lhe havia enviado, quando ele estava "com" (prós) o Pai, agora os estava enviando, pois estavam igualmente "com" (prós) o Pai (Jo 20:21). Os discípulos "alegraram-se, portanto, ao verem o Senhor" (Jo 20:20). Nisso se cumpriu o que havia prometido, "a vossa tristeza se converterá em alegria" (Jo 16:20).

O amplo uso da preposição prós ao longo do evangelho para falar da relação de pertença e intimidade entre Jesus e o Pai, e entre ele e seus seguidores, evidencia também a unidade estrutural do evangelho de João. O tema da associação íntima e pertença se aprofunda nos discursos de "despedida" (Jo 13-17). No entanto, se acha enraizado ao longo de toda a narrativa do quarto evangelho e funciona como um elemento organizador de toda a narrativa, como veremos na sequência.

\section{O chamado a permanecer}

Em João 15, Jesus prossegue seu discurso sobre a íntima e direta ligação entre si e os discípulos por meio da alegoria ou "comparação" da videira (HENDRIKSEN, 2007, p. 294). Ela é uma metáfora recorrente para o Israel de Deus (cf. Sl 80:8-19; Is 5). Por meio do pacto, os filhos Israel estavam em direta associação com Deus. O santuário era um meio para a consumação da presença constante divina entre eles (Êx 25:8). No contexto da nova aliança, Paulo afirma que os que creem em Jesus são "enxertados" como ramos nessa árvore (Rm 11:17-18; Gl 3:29), o que na linguagem de João equivale a ser "filhos" de Deus por meio da fé em Jesus.

A alegoria de João 15 atesta a unidade entre Jesus e os discípulos, construída pela presença do Espírito sobre os que creem, como orgânica e inquebrantável. A permanência do ramo ou galho na videira é a condição para que esteja vivo e produza fruto. Mediante essa conexão, a seiva que flui pelo caule capacita o ramo a produzir fruto. A metáfora presumida da seiva é uma alusão ao Espírito, que flui por meio da ligação entre Jesus e seus seguidores. Bruce (1981, p. 264) afirma que a ideia de "inerência mútua e da habitação recíproca" entre Cristo e seu povo recebeu expres- 
são repetida no capítulo 14 e é aprofundada na alegoria da videira e dos ramos em João 15. A alegoria nesse sentido serve como uma ilustração da ligação vital e geracional entre Jesus e seus seguidores.

A mesma relação definida com a expressão "face a face" (prós) é referida com a alegoria da videira, enfatizando a inerência e ligação íntima. Os discípulos estão ligados a Jesus de forma orgânica e vital. No capítulo 15, João usa o verbo ménō ("permanecer", "ficar", "residir", "sustentar") 11 vezes. Este é um verbo recorrente nos escritos joaninos. Das 118 vezes em que ocorre no Novo Testamento, 40 vezes é empregado no quarto evangelho e outras 24 em 1 João. Juntos, os sinóticos o empregam só 12 vezes; Atos 13 vezes e as epístolas paulinas 17 vezes (cf. SHOEMAKER, 2011, e-book). A condição para "permanecer" em Cristo é guardar os mandamentos (Jo 15:10), especialmente o do amor (15:12), e o resultado é "dar muito fruto" (15:5).

Em João 17:1, quando Jesus se refere à "hora" que é chegada, fica claro no contexto que está em perspectiva a "hora de sua morte, ressurreição, ascensão e coroação, sua plena partida para o Pai" (HENDRIKSEN, 2007, p. 348). Em João 17:3, Jesus declara que "a vida eterna é esta: que conheçam a ti, o único Deus verdadeiro, e a Jesus Cristo, a quem enviaste". A mesma relação definida antes como "face a face", de estar "no Pai", aqui é referida em termos de conhecer (ginoskō), em intimidade e proximidade, conhecer por experimentar. Esse conhecimento só é possível porque Jesus tem "dado" a palavra de Deus aos discípulos (Jo 17:14) e manifestado a eles a "glória" de Deus (17:22). Por isso, é possível ocorrer a relação mais íntima: "eu neles, e tu em mim, a fim de sejam aperfeiçoados em unidade" (17:23). Essa "unidade" não é simplesmente união em contraste com desunião, mas unidade na relação "face a face", possibilitada pela "morada" dos discípulos em Deus, e de Deus neles (Jo 14:2, 23). Tal unidade resulta do novo relacionamento entre Deus e os seres humanos, que antes estavam longe, mas agora estão próximos.

Essa pertença e permanência em Deus só é possível porque Jesus conquistou, pela virtude de sua morte, o direito de que os que creem sejam feitos membros da família e do círculo íntimo da divindade. A proximidade e intimidade com Deus é a condição para que os seguidores de Jesus sejam plenos de graça e amor, o que evidencia para o mundo o novo nascimento e a harmonia com o mandamento do amor (Jo 3:6; 13:34-35).

\section{A unidade do evangelho}

O tema da proximidade e pertença entre Jesus e os discípulos, portanto, é o centro da unidade narrativa de João 13-17. De fato, é aprofundado nos discursos de despedida e claramente conecta esta unidade narrativa ao 
prólogo. Há evidências de que a mesma temática é também desdobrada na primeira seção narrativa.

Na primeira unidade narrativa do evangelho (Jo 2-12), Jesus afirma a Nicodemos que se alguém não "nascer da água e do Espírito não pode entrar no reino de Deus" (3:5). Com isso, indica que a entrada no reino ou na família de Deus como "filho" requer uma nova gestação, mediante o batismo do Espírito, o Consolador a ser provido pelo Pai (Jo 17). A proximidade e pertença com Cristo depende necessariamente da experiência de crer e se tornar filho de Deus (Jo 1:12). "Tornar-se um filho é um longo processo" que depende do "lavar purificador do Espírito" (HENDRIKSEN, 2007, p. 134). A fala de Cristo evoca uma imagem com forte conotação de proximidade entre a divindade e a humanidade. Na tradição de Israel, Adão é feito um "ser vivo" e "filho de Deus" mediante o "sopro" (ruah; pneuma; "espírito") de Yahweh (Gn 2:7; Lc 3:38).

A temática da proximidade e pertença ainda se aprofunda no diálogo com a mulher samaritana, em que o batismo na água segue como metáfora do nascimento espiritual (Jo 3:5). Jesus afirma que aquele que bebe da água que ele dá "nunca mais terá sede" (Jo 4:14). A mulher havia indagado se seria Jesus maior do que o "pai" Jacó que dera o poço a seus "filhos" (4:12), segundo a tradição dos samaritanos (BORCHERT, 1996, p. 204). Jacó é pai por ter provido a água do poço para seus filhos. No entanto, Jesus afirma que de si flui água capaz de saciar a sede para sempre. Borchert (1996, p. 205) observa que "o simbolismo de Jesus escapa completamente da percepção da mulher que assim como Nicodemos não entendeu o sentido do novo nascimento". Novamente, o dito de Cristo ecoa a tradição de Israel. No deserto a caminho do Sinai, os filhos de Israel beberam da água da "rocha" em Meribá (Ex 17:6), e a "rocha era Cristo" (1Cor 10:4). Após esse evento, chegaram ao Sinai onde Deus fez aliança com Israel, que deixa de ser propriedade do Faraó para nascer como filho para Deus (Ex 19:6; Os 11:1).

Na sequência, após a cura do paralítico, explicando sua missão, Jesus atesta que os judeus devem "vir a mim" (erkomai prós me) para terem vida (Jo 5:40). O uso da preposição prós indica que ir a Cristo implica estar "face a face" com ele, como condição para se ter vida eterna. No contexto da multiplicação dos pães, vai mais longe ainda em definir essa relação entre ele e seus seguidores: "quem comer a minha carne e beber o meu sangue tem a vida eterna" (Jo 6:54). Neste contexto, ele indica que aquilo que "eles buscavam na Escritura [com o estudo disciplinado da Torá] podiam encontrar unicamente em sua pessoa, que é a fonte da vida eterna (cf. Jo 3:16; 17:2)" (BORCHERT, 1996, 246).

No contexto da Festa dos Tabernáculos, em que se rememoravam as condições hostis do deserto com falta de água e pão, Jesus convida os judeus: 
"Se alguém tem sede, venha a [prós, 'face a face'] mim e beba" (7:37). O simbolismo de se beber da água segue numa linha contínua ao longo do texto e indica que a relação íntima e orgânica com Cristo é o único caminho para se tornar filho de Deus, segundo a teologia do quarto evangelho (cf. Jo 1:12). Em João 8:31, 32, Jesus reitera: "Se vós permanecerdes na minha palavra, sois verdadeiramente meus discípulos, e conhecereis a verdade e a verdade vos libertará". A experiência de "permanecer" é retomada na alegoria da videira (Jo 15). Em João 10:9, no discurso do Bom Pastor, ele anuncia: "Eu sou a porta. Se alguém entrar por [diá, 'através', 'por meio de'] mim, será salvo". Novamente indica a si mesmo como a única fonte e caminho da vida eterna e da relação de pertença e filiação com Deus (TENNEY, 1981, p. 107).

Desta maneira, a relação íntima, inerência ou morada recíproca, entre Cristo e o Pai e que se reproduz entre Cristo seus discípulos, sendo proporcionada pela encarnação de Cristo e pela descida do Consolador, é um tema recorrente e unificador ao longo de todo o quarto evangelho. Esse tema se inicia no prólogo e se estende pela primeira seção (Jo 1-12, Jesus e o mundo) e igualmente pela segunda (Jo 13-17, Jesus e os discípulos). No prólogo, afirma-se que o Lógos estava "face a face com Deus" (Jo 1:1), fez-se "carne" e "habitou" (skēnoō, também "face a face") entre os seres humanos (Jo 1:14).

Entretanto, apesar de o quarto evangelho ter a relação íntima entre Jesus e os discípulos como um tema estruturante, nele Jesus não toca as pessoas. Nos sinóticos, frequentemente toca as pessoas para operar milagres (Mt 8:3, 4; 9:18, 20, 25; 14:29-31; 20:34; Mc 1:29-31; 5:21-43; 9:25-27; Lc 4:40; 7:14, $15 ; 8: 4-56)$. Ele tocou os leprosos e os mortos, e a mulher com fluxo de sangue o tocou, apesar das restrições cerimoniais judaicas (cf. Lv 15:25-30; MARTIN, 1985, p. 227). Porém, em João, Jesus não toca as pessoas em seus sinais (Jo 2:1-11; 4:46-54; 5:1-15; 9:6, 7; 11:39-44). Isso parece sugerir ao leitor o mistério da relação íntima como algo que prescinde do toque e da presença tangível de Cristo e mesmo dos apóstolos que estiveram com ele face a face. Jesus afirmou a Tomé serem "bem-aventurados os que não viram e creram" (Jo 20:29; o texto não afirma que Tomé chega a tocar o Mestre, mas que, ao ver, creu). Osborne e Comfort (2007, p. 292) afirmam que essa segunda bem-aventurança joanina exalta o mérito daqueles que não demandam a experiência dos sentidos para crer em Jesus. A inclusão da experiência de Tomé de exigir ver e tocar para crer e a decorrente exaltação por parte de Cristo daqueles que não virem e mesmo assim crerem destacam que a fé mais elevada, de fato, toma lugar à parte da evidência dos sentidos. O quarto evangelho, portanto, "pretende despertar tal crença que é paralela à das primeiras testemunhas, mas sem o privilégio das evidências tangíveis" (BORCHERT, 1996, p. 316). De fato, a presença ou proximidade íntima estendida aos discípulos no contexto da "partida" de Cristo destaca exatamente o mérito deste tipo de fé. 
Desta forma, a primeira unidade temática de João assim como a segunda, e mais amplamente ainda o discurso de despedida, evidenciam uma estrutura narrativa no quarto evangelho. Ela é criada pela temática da relação íntima e de pertença entre Jesus e seus seguidores, ou aqueles que creem nele como messias e que, mediante isso, são feitos filhos de Deus (Jo 1:12). Apesar das inconsistências e rupturas cronológicas e geográficas, a narrativa evidencia uma deliberada unidade teológica e conceitual.

\section{Conclusão}

Os estudos histórico-críticos despertaram a percepção de diversas imperfeições nos textos bíblicos, especialmente no evangelho de João. Essas imperfeições em João incluem lacunas e informações desencontradas no que diz respeito a dados cronológicos e geográficos, além de termos incomuns usados sem continuidade. Esses estudos também indicaram diferentes fontes por trás do texto final do evangelho. Além disso, propuseram tentativas de se reorganizar as diversas narrativas de forma a prover um fluxo cronológico e topográfico mais convincente.

Na sequência desses estudos, análises literárias e teológicas, porém, têm contribuído para a percepção de uma estrutura intencional e deliberada acima das imperfeições textuais desse evangelho. Este artigo explorou o programa estabelecido no prólogo do evangelho (Jo 1:11-12) em que a rejeição e a crença a Jesus se apresentam, nessa ordem, como elementos organizadores ao longo de todo o texto. O tema da relação íntima e de pertença se aprofunda na segunda unidade narrativa (Jo 13-17), mas está igualmente evidente na primeira unidade (Jo 2-12).

A temática da íntima relação, portanto, evidencia uma organização literária e teológica, em contraste com o estado imperfeito da narrativa cronológica e geográfica do evangelho, em sua presente forma. Assim, apesar da percepção dos estudos histórico-críticos de diversas rupturas textuais no quarto evangelho, uma unidade teológica está claramente definida. Beasley-Murray (1987, p. xci) afirma que, do ponto de vista da estrutura, há sinais de um "cuidadoso trabalho" teológico e narrativo para a forma final do texto do quarto evangelho.

A despeito dos debates sobre as inconsistências narrativas e informações geográficas e topográficas desencontradas, o quarto evangelho apresenta uma clara estrutura temática, a qual é atestada pela antecipação de seus grandes temas no prólogo os quais se desdobram nas duas seções narrativas. $\mathrm{O}$ tema da proximidade e relação íntima entre Jesus e os discípulos reforça essa percepção.

O debate acerca da desorganização ou unidade narrativa precisa levar em consideração que o escritor do quarto evangelho estava mais interessado 
em unidades temáticas e literárias do que em informações topográficas e geográficas, ou mesmo cronológicas. Ele submete essas categorias ao plano maior de sua narrativa que tem a ver com a divindade e proximidade de Cristo a Deus, a qual se franqueia aos discípulos em virtude da relação de fé entre eles e o mestre.

Assim, o tema da habitação recíproca e da relação íntima ou inerência mútua atravessa todo o evangelho e fortalece a ideia da unidade temática e literária do livro. Essa relação de unidade e pertença, possibilitada pela descida do Consolador, é detalhada e aprofundada no discurso de despedida, mas já está evidente no prólogo e nos discursos de Cristo desde o início de seus sinais.

\section{Siglas}

ARA = Almeida Revista e Atualizada.

ARC = Almeida Revista e Corrigida.

NTLH $=$ Nova Tradução na Linguagem de Hoje.

NVI = Nova Versão Internacional:

\section{Referências}

ARNDT, W. F.; GINGRICH, F, W. A Greek-English Lexicon of the New Testament and Other Early Christian Literature. Chicago: University of Chicago Press, 1960. p. $509-11 ; 716-718$.

AUNE, D. E. The Cultic Setting of Realised Eschatology in Early Christianity. Leiden: E. J. Brill, 1972.

BALZER, D. Glory and temple in John's Gospel with particular reference to John 1:14. 2008. 138 p. Dissertação de Mestrado em Teologia - Presbyterian Theological Centre. Sidney, 2008.

BARRETT, C. K. The Gospel According to St John: an introduction with Commentary and Notes on the Greek Text. Londres: SPCK, 1967.

BARTON, S. C. Historical Criticism and Social-Scientific Perspectives in New Testament Study. In: J. B. G. (Org.). Hearing the New Testament: Strategies for Interpretation. $2^{\text {nd }}$ ed. Grand Rapids; Cambridge: William B. Eerdmans Publishing Company, 2010. p. 61-89.

BEASLEY-MURRAY, G. R. John. Waco, TX: Word Books, 1987. (Word Biblical Commentary, 36).

BEUTLER, J. Evangelho segundo João: Comentário. São Paulo: Loyola, 2016.

BÍBLIA Sagrada: Antigo e Novo Testamento. Trad. João Ferreira de Almeida. Ed. revista e corrigida no Brasil. Barueri: Sociedade Bíblica do Brasil, 1969. 
BÍBLIA Sagrada: Antigo e Novo Testamento por João Ferreira de Almeida. 2.ed. rev. e atualizada no Brasil. Barueri: Sociedade Bíblica do Brasil, 1993.

BÍBLIA Sagrada: Antigo e Novo Testamento. Nova Tradução na Linguagem de Hoje. Barueri: Sociedade Bíblica do Brasil, 2000.

BÍBLIA. Sagrada: Antigo e Novo Testamento. Nova Versão Internacional. São Paulo: Sociedade Bíblica Internacional, 2001.

BROWN, R. E. The Gospel According to John. Garden City: Doubleday, 1966. (The Anchor Bible).

BRUCE, F. F. João: introdução e comentário. São Paulo: Mundo Cristão, 1981.

BORCHERT, G. L. John 1-11: an Exegetical and Theological Exposition of Holy Scripture. Nashville: Broadman \& Holman Publishers, 1996. (The New American Commentary, 25).

CARSON, D. A. O Comentário de João. São Paulo: Shedd Publicações, 2011.

EHRMAN, B. D. Textual Criticism of the New Testament. In: GREEN, J. B. (Org.). Hearing the New Testament: Strategies for Interpretation. Grand Rapids; Cambridge: Eerdmans, 1995. p. 127-145.

HENDRIKSEN, W. John. Grand Rapids, MI: Baker Academic, 2007. (New Testament Commentary).

KOSTENBERGER, A. J. A Theology of John's Gospel and Letters. Grand Rapids, MI: Zondervan, 2009. (Biblical Theology of the New Testament).

LENSKI, R. C. H. The Interpretation of St. John's Gospel. Minneapolis: Augsburg Publishing House, 1961.

LOUW, J.; NILDA, E. Léxico Grego-português do Novo Testamento: baseado em domínios semânticos. Barueri, SP: Sociedade Bíblica do Brasil, 2013.

MARTIN, J. A. Luke. In: J. F. Walvoord \& R. B. Zuck (Orgs.). The Bible Knowledge Commentary: An Exposition of the Scriptures. Wheaton: Victor Books, 1985. v. 2, p. 199-294.

METZGER, B. M. A Textual Commentary on the Greek New Testament. New York: United Bible Societies, 1994.

MLAKUZHYIL, G. The Christocentric Literary Structure of the Fourth Gospel. Roma: Gregorian \& Biblical Press, 2011.

MORRIS, L. The Gospel According to John. Grand Rapids: Eerdmans, 1995. (New International Commentary on the Old and New Testament).

NEYREY, J. H. "Spaces and Places, Whence and Whither, Homes and Rooms: 'Territoriality' in the Fourth Gospel". Biblical Theology Bulletin, Thousand Oaks, v. 32, n. 2, p. 60-75, 2002.

OSBORNE, G.; COMFORT, P. W. John and 1, 2, and 3 John. Carol Stream: Tyndale House Publishers, 2007. (Cornerstone Biblical Commentary, 13).

RUSCONI, C. Dicionário do Grego do Novo Testamento. 4.ed. São Paulo: Paulus, 2011. p. 303-304; 391-393. 
SHOEMAKER, M. The Theology of the Four Gospels. Bloomington: WestBow Press, 2011.

TEEPLE, H. M. The Literary Origin of the Gospel of John. Evanston: Religion and Ethics Institute, 1974.

TENNEY, M. C. John. In: FRANK E. G. (Ed.). The Expositor's Bible Commentary: John \& Acts. Grand Rapids: Zondervan, 1981. v. 9, p. 1-203.

Artigo submetido em 05.05.2020 e aprovado em 18.06.2021.

Vanderlei Dorneles é Doutor em Ciências da Comunicação (USP, 2009) e Doutor em Ciências da Religião pela Universidade Metodista de São Paulo (2020). É pós-doutor em Teologia pela Andrews University. Atua como docente e coordenador da Faculdade de Teologia do Unasp Campus Engenheiro Coelho. Orcid.org/0000-0001-8147-4838. E-mail: vanderlei. dorneles@unasp.edu.br

Endereço: Av. Jacarandá, 641, Res. Lagoa Bonita 13448-902 - Engenheiro Coelho, São Paulo 